\title{
Prejudice and Discrimination From Two Sides: How Do Middle-Eastern Australians Experience It and How Do Other Australians Explain It?
}

\author{
Anne Pedersen, ${ }^{1}$ Kevin Dunn, ${ }^{2}$ James Forrest ${ }^{3}$ and Craig McGarty ${ }^{1}$ \\ ${ }^{1}$ Murdoch University, Australia \\ ${ }^{2}$ University of Western Sydney, Australia \\ ${ }^{3}$ Macquarie University, Australia
}

\begin{abstract}
There is little quantitative research regarding the causes and expression of prejudice and discrimination against Middle-Eastern Australians. We report two studies, one from the perspective of new settlers and a second from the perspective of host communities. The first found that Middle-Eastern Australians reported more discrimination compared with non-Middle-Eastern Australians. More discrimination was reported by Middle-Eastern males compared with females on dealings with the police, disrespect, namecalling, and distrust. The second study, focusing on attitudes of other Australians, found that they were more likely to perceive that Middle-Eastern Australians would be discriminated against compared with their own social group. When the non-Middle-Eastern Australians in the survey were asked for reasons why Australians from the Middle East were discriminated against, the most prevalent themes were (a) perceived conflict with 'Australian values', (b) fear of Muslims, (c) fear of terrorism, (d) negative media and (e) fear of difference. The overall finding that there are strong levels of public acknowledgment of the higher discriminatory burden endured by Middle-Eastern Australians is seen as a positive in terms of (1) community action to address that burden through (2) counteracting the socially negative attitudes that underpin discrimination in some Australian communities.
\end{abstract}

Keywords: racism, discrimination, Arab, Muslim

There is a growing body of research examining prejudice and discrimination against different minority groups within Australia, such as Indigenous Australians (Barlow, Louis, \& Hewstone, 2009), Asian and Jewish Australians (Dunn, Forrest, Burnley, \& McDonald, 2004), Muslim Australians (Ata, Bastian, \& Lusher, 2010) and asylum seekers (Haslam \& Pedersen, 2007). There is, however, little empirical research specifically examining the experience of discrimination (the behavioural component of prejudice) and the attitudes underpinning such prejudicial actions (from the point of view of the local community). To address these issues, we present here two linked studies. Study 1 examines discrimination experienced by Middle-Eastern Australians and the gendered nature of that experience. Study 2 examines the other side of the coin: the attitudes of non-Middle-Eastern Australians towards Middle-Eastern Australians.
Qualitative evidence has noted the rise in prejudice and discrimination against Middle-Eastern Australians since the events of 9/11 in New York (HREOC, 2004). Prejudice has also been affected by the increasing number of asylum seekers from the Middle East because of the hostility many Australians feel about asylum seekers generally (see Klocker, 2004). Forrest and Dunn (2007) found that over a quarter of their participants identified Middle-Eastern Australians and Muslims generally as 'out-groups' to the question 'which cultural groups don't belong in Australia'.

There are well documented instances of people of Middle Eastern appearance being attacked because of their ethnicity (e.g., Dreher, 2005; Dunn, 2009; HREOC, 2004). Furthermore, there is increasing evidence of discrimination against them in the workforce because of their ethnicity (e.g., Colic-Peisker, 2009; Tilbury \& ColicPeisker, 2006). In a recent Australian field experiment that

Address for correspondence: Anne Pedersen, School of Psychology, Murdoch University, Murdoch WA 6150, Australia. E-mail: A.Pedersen@murdoch. edu.au 
measured the success of job applications, it was found that people with Middle Eastern names were less likely to get a call-back than were applicants with Anglo-Saxon names or more established groups such as Italians (Booth, Leigh, \& Varganova, 2009). Children from Middle Eastern backgrounds as young as 7 years old have reported experiences of discrimination (Runions, Priest, \& Dandy, 2011).

It has also been suggested that Arab/Muslim women are more likely to experience prejudice than their male counterparts since the $9 / 11$ attacks. As noted by HREOC (2004), 'Muslim women who wear traditional Islamic dress were especially afraid of being abused or attacked. Many have restricted their movements and reported becoming more isolated since September 11' (p. 3). The Islamic Women's Welfare Council of Victoria (IWWCV; 2008) also reported that Muslim women, particularly those wearing head coverings such as the hijab or who were darker skinned, reported greater prejudice and discrimination against them, especially in the form of verbal abuse. Conversely, other research has found that Muslim women are viewed more favourably than Muslim men by the general public (Pedersen \& Hartley, 2012). This may be linked to two dominant and gendered caricatures of Muslims in western countries. The masculine stereotype is highly chauvinistic, with values at odds with those of a liberal democratic state; the feminine caricature is one of passivity, silence and oppression concealed behind a veil (Aly, 2007). The former inculcates threat and fear; the latter pity or disappointment (Deen, 1995).

Our interest is therefore in two linked but underresearched issues. Study 1 sets the context by establishing forms of discrimination experienced by Australians of Middle Eastern backgrounds. Study 2 explores how the attitudes of the perpetrating group relate to such prejudice and discrimination.

\section{Study 1}

The first study derives from a national random sample survey; here, we investigated reported instances of discrimination experienced by Australians born in the Middle East. We were specifically interested in whether Middle-Eastern Australians reported higher rates of discrimination than other Australians; and whether there were differences in the experience of discrimination between males and females.

\section{Participants}

Data were collected from participants aged 18 and over by telephone state by state between 2001 and 2008: New South Wales and Queensland in 2001; Victoria in 2006; South Australia, Australian Capital Territory and Northern Territory, and Perth in 2008 (the rest of Western Australia has not yet been surveyed). Within the full sample ( $N$ $=12517)$, 115 participants were born in countries in the Middle East: Egypt, Iran, Iraq, Kuwait, Lebanon, Syria and Turkey. They represented $0.9 \%$ of the sample, compared with $1.0 \%$ born in these countries at the 2006 Census (Australian Bureau of Statistics [ABS], 2010). Although there were a range of education levels, the sample slightly overrepresented those with tertiary qualifications (46\% cf. $43 \%$ in the 2006 Census). The weighted survey results showed the same proportion of males (49\%) as the census. Age categories of participants were close to the relevant census figures: $30 \%$ of the sample was aged $18-34$ (31\% in the Census); $42 \%$ were aged 35-64 (50\%) and 18\% were aged 65 or more $(19 \%)$. With regard to the whole sample, those with tertiary qualifications (36\%) were somewhat under-represented, but the male-female ratio $(51 \% \mathrm{fe}-$ male) was consistent with that of the national population. Age composition was $30 \%$ in the 18-34 category; 52\% were aged $35-64$; and $18 \%$ were 65 or more.

\section{Measures}

Nine questions were asked about how often have you experienced discrimination because of your own ethnic origin' in the following situations (Dunn et al., 2004): in institutional settings - the workplace, education, housing and policing as well as in 'everyday' situations and in 'everyday' settings — in a shop or restaurant, at sports events or other public event; furthermore, that participants were treated with disrespect, with mistrust, or were called names or otherwise insulted. The response option range was never, hardly ever, sometimes, often, and very often.

\section{Procedure}

Informed consent was obtained prior to each interview and a contact person's telephone number provided for any follow-up on the part of the person being interviewed. The response rate varied by state within a range from 51-55\%. The surveys took seven to eight minutes on average to complete, using 31 questions on experiences of discrimination, cross-cultural contact, attitudes to diversity and out-groups (Dunn et al., 2004). Eight socio-demographic questions were included on gender, age, birthplace, languages spoken, Indigenous status, and level of education.

\section{Results}

A comparison of experiences of discrimination highlighted the greater impact on Middle Easterners over other Australians. Table 1 contains the descriptive measures, including means and standard deviations. From Table 1, in every instance, Middle Easterners reported more discrimination in both institutional and everyday contexts than other Australians. ${ }^{1}$ Two findings in Table 1 stand out in particular. One was the relatively high levels of discrimination that occur in educational contexts, which is an important sphere of cross-cultural contact where there is greater opportunity for discrimination based on ethnic origins (Dunn et al., 2003). The other was the relatively high levels of everyday incivilities, such as being treated disrespectfully and name-calling. 


\begin{tabular}{|c|c|c|}
\hline \multicolumn{3}{|c|}{$\begin{array}{l}\text { Experiences of Discrimination by Middle-Eastern and non-Middle-Eastern Australians in Specific } \\
\text { Contexts: Descriptive and ANOVA Results }\end{array}$} \\
\hline Location & Mean/(SD) & ANOVA \\
\hline Work & $\begin{array}{l}\text { Middle Eastern 1.7(1.0) } \\
\text { Non-Middle Eastern 1.2 (0.7) }\end{array}$ & $F(1,9087)=44.6 ; p<.001$ \\
\hline Education & $\begin{array}{l}\text { Middle Eastern } 1.8(1.4) \\
\text { Non-Middle Eastern1.3 (0.7) }\end{array}$ & $F(1,9087)=52.9 ; p<.001$ \\
\hline Housing & $\begin{array}{l}\text { Middle Eastern } 1.3(0.8) \\
\text { Non-Middle Eastern1.1 (0.4) }\end{array}$ & $F(1,9087)=31.7 ; p<.001$ \\
\hline Police & $\begin{array}{l}\text { Middle Eastern } 1.7 \text { (1.2) } \\
\text { Non-Middle Eastern1.1 (0.5) }\end{array}$ & $F(1,9087)=152.4 ; p<.001$ \\
\hline Shopping/restaurants & $\begin{array}{l}\text { Middle Eastern } 1.6(0.9) \\
\text { Non-Middle Eastern } 1.2(0.6)\end{array}$ & $F(1,9087)=33.1 ; p<.001$ \\
\hline Sport/public places & $\begin{array}{l}\text { Middle Eastern } 1.6(1.0) \\
\text { Non-Middle Eastern1.2 (0.7) }\end{array}$ & $F(1,9087)=31.6 ; p<.001$ \\
\hline Disrespect & $\begin{array}{l}\text { Middle Eastern } 2.0(1.1) \\
\text { Non-Middle Eastern1.3 (0.7) }\end{array}$ & $F(1,9087)=97.7 ; p<.001$ \\
\hline Distrust & $\begin{array}{l}\text { Middle Eastern } 1.7(1.1) \\
\text { Non-Middle Eastern1.2 (0.6) }\end{array}$ & $F(1,9087)=88.4 ; p<.001$ \\
\hline Name calling & $\begin{array}{l}\text { Middle Eastern } 1.8(1.1) \\
\text { Non-Middle Eastern1.3 (0.7) }\end{array}$ & $F(1,9087)=39.0 ; p<.001$ \\
\hline
\end{tabular}

\section{Table 2}

Experiences of Discrimination by Middle-Eastern Males and Gemales in Specific Contexts: Descriptive and ANOVA Results

\begin{tabular}{lll}
\hline Location & \multicolumn{1}{c}{ Mean/(SD) } & \multicolumn{1}{c}{ ANOVA } \\
\hline Work & $1.8(1.3)$ & $F(1,121)=0.2 ; p=.64$ \\
Education & $2.0(1.6)$ & $F(1,121)=0.7 ; p=.40$ \\
Housing & $1.5(1.1)$ & $F(1,121)=0.0 ; p=.99$ \\
Police & Male 2.0 (1.3) & $F(1,121)=11.5 ; p<.001$ \\
& Female 1.2 (0.8) & \\
Shopping/restaurants & Both 1.7 (1.2) & \\
Sport/public places & $1.6(0.9)$ & $F(1,121)=0.0 ; p=1.0$ \\
Disrespect & Male 2.2 (1.1) & $F(1,121)=18.6 ; p<.001$ \\
& Female 1.5 (0.8) & \\
& Both 2.0 (1.1) & \\
Distrust & Male 1.9 (1.2) & $F(1,121)=2.9 ; p=.09$ \\
& Female 1.5 (0.8) & \\
& Both 1.7 (1.1) & \\
Name calling & Male 2.0 (1.1) & $F(1,121)=6.4 ; p=.01$ \\
& Female 1.5 (0.9) & \\
& Both 1.8 (1.1) & \\
\hline
\end{tabular}

Results also showed significant gender differences with regard to three items (dealings with the police, disrespect, and name-calling) and one marginal difference (distrust) but these findings are contrary to previous suggestions (HREOC, 2004) that Muslim women are generally exposed to more discrimination than males. Table 2 sets out the descriptives and means/standard deviations; where significant differences exist, these means/standard deviations are separated out.

\section{Discussion}

Other than with the experience of discrimination by gender, the results in Table 1 generally align with findings of researchers using qualitative methodologies, such as interviewing and focus groups (Poynting, Noble, \& Ang, 2004). The Freedom of Religion and Belief national inquiry similarly found that Muslim Australians had a heightened exposure to discrimination (Bouma, Cahill, Dellal, \& Zwartz, 2011). In a recent Perth study with Muslim Australians, it was found that Middle Eastern Muslims reported significantly more discrimination than other Muslims in four instances: housing, dealings with the police, shopping, and general public spaces (Salleh-Hoddin \& Pedersen, in press). These studies, together with our findings, indicate that it is harder for people of Middle Eastern appearance to avoid discrimination compared with other Australians.

Findings on police interactions align with research and inquiry hearings that have commented on poor relations between Middle-Eastern Australian youth and police in some jurisdictions (HREOC, 2004; Islamic Council of New South Wales, 2004). Male youth may also have a heightened exposure to disrespect and name-calling, reflecting scholarship that has flagged issues around incivilities performed, and experienced, by Middle-Eastern Australian youth (Poynting, Noble, \& Tabar, 1999).

In short, while our data indicate a relatively low general exposure of Middle-Eastern Australians to discrimination, what they do experience is at rates that are well above those of non-Middle-Eastern Australians. Also, Middle-Eastern males have a stronger exposure to discrimination in some spheres of life: in dealings with police and in everyday experiences of discrimination that manifest through everyday incivilities.

\section{Study 2}

Results from Study 1 led to the next question: how do nonMiddle-Eastern Australians explain and respond to prejudice against Middle-Eastern Australians? Study 2 pursued two aims. The first was to investigate perceptions of discrimination against Middle-Eastern Australians. Would there be a difference between the perception of 
discrimination against one's own group, and perceived discrimination against Middle-Eastern Australians? If participants did perceive discrimination against MiddleEastern Australians, what reasons would they give? Our second aim was to investigate any difference in prejudice against Middle-Eastern males compared to MiddleEastern females. Given the results of Study 1, coupled with the findings of Pedersen and Hartley (2012), and bearing in mind that many Australians do not differentiate between 'Middle Eastern' and 'Muslim' (HREOC, 2004), we predicted that Middle-Eastern males would be judged more harshly than Middle-Eastern females.

\section{Participants}

Participants were recruited from Perth and Sydney. In the decade from January 2001 to January 2011, 1,446,113 new settlers were accepted for permanent residence in Australia according to the Department of Immigration's Settlement Database (DIAC, 2011). Of these, 31\% went to Sydney, $25 \%$ to Melbourne, $12 \%$ to Perth, $8.4 \%$ to Brisbane and $5.5 \%$ to Adelaide. We sampled from Sydney, as the biggest destination, and from Perth, which is the most prominent city in a second tier of metropolitan growth regions.

Using the ABS (2010) Socio Economic Indexes for Areas (SEIFA) scores, four suburbs in each of Perth and Sydney were chosen. In each city, there was one high, one low and two medium socio-economic status (SES) suburbs chosen at random (more residents are classified as medium SES). In an attempt to increase representativeness, care was taken to use suburbs that had average populations of Middle-Eastern Australians; that is, if suburbs randomly chosen were not representative, they were not used. This was important because previous research found that too much or too little contact can affect attitudes towards marginalised groups (see Khan \& Pedersen, 2010, regarding attitudes towards African immigrants). Thus, it was important not to select suburbs with an above-average, or below-average, number of Middle-Eastern Australians. Within the chosen suburbs, streets were randomly chosen.

One hundred and ninety participants replied to a survey in Perth and Sydney; the response rate was higher in Perth (58\%) compared with Sydney (42\%). These participants were well educated, with over half holding a bachelor's degree or higher. There were $65.2 \%$ females and 34.8\% males. Most participants were Caucasian/Europeans (90.7\%), followed by Asians (4.4\%). The remaining participants were African, Pacific Islander and 'other'. The mean age was $53.4(S D=15.4)$. Thus, this sample was somewhat older and more educated than the general population (ABS, 2010), with a higher proportion of women who responded.

\section{Measures}

A mail-out survey was used in line with similar research (e.g., Pedersen \& Hartley, 2012); thus, we could then make valid comparisons between studies. The survey included the following sections:

Prejudice against Middle-Eastern females and males in Australia. Two attitude thermometers taken from Wolsko, Park, Judd, and Bachelor (2003) were used: 0 degrees equated to extremely unfavourable and 100 degrees to extremely favourable. After reversal of the scores, high scores indicated higher prejudice.

Self-identified discrimination. Participants were asked whether they faced discrimination (e.g., ethnic origin, religion, gender, age, sexuality). If their response was yes, they were asked which type of discrimination affected them personally.

Discrimination against self. Participants who reported that they did face discrimination were asked the same nine discrimination items as in Study 1, but the questions were prefaced with 'I have experienced discrimination because of my social group (that is, the category selected above) in the following situations .... . High scores indicated higher discrimination.

\section{Discrimination against Middle-Eastern Australians.}

The same nine discrimination questions were asked as in Study 1 except the questions referred to perceptions as to whether Australians of Middle Eastern descent experience discrimination. High scores indicated a higher perception of discrimination.

Socio-demographics. Participants were asked to specify whether they came from Perth or Sydney, age in years, gender $(1=$ male, $2=$ female), suburb (to glean sociodemographic information) education level $(1=\operatorname{did}$ not complete secondary school, to $6=$ higher degree, e.g., $\mathrm{PhD}$, Masters), and ethnic background (African, Asian, Caucasian/European, Aboriginal and/or Torres Strait Islander, Indian, Middle Eastern, Pacific Islander, Other).

Qualitative section. Participants were asked: 'If you believe that Middle-Eastern Australians are likely to face potential discrimination, could you please explain in a few words why you think this may occur?' The responses were then categorised by an independent research assistant, unaware of the aims of the present study, thematically according to the explanations given.

\section{Procedure}

Following ethical approval and informed consent from the Research Ethics Committee at Murdoch University in Perth, a questionnaire and a covering letter were delivered to 800 participants aged 18 years and above in both cities ( $n=1,600)$ consistent with similar research (e.g., Khan \& Pedersen, 2010). Half the covering letters requested response by a female and the other half male, although either sex could respond if the preferred sex was unavailable. Two weeks later a reminder letter was delivered. A total of 190 questionnaires were returned, a response rate of $12 \%$. 


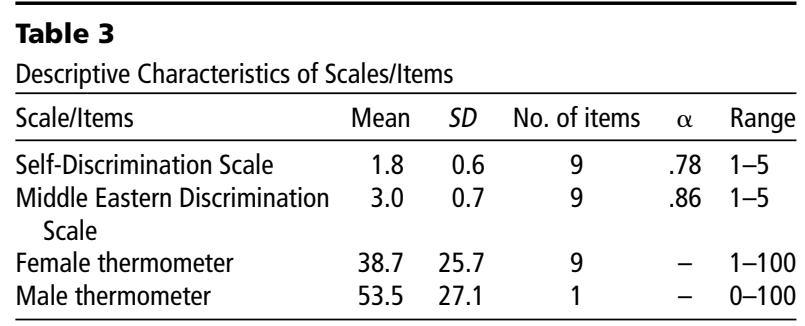

\section{Results}

Compared with Sydney, participants from Perth reported that they were significantly more right wing on most issues, $t(134)=3.0, p=.003$, less educated, $t(171)=-2.6$, $p=.011$, reported more personal discrimination, $t(61)=$ $2.4, p=.021$, and reported less positive views about Middle-Eastern females, $t(144)=-2.1, p=.033$.

\section{Scale Descriptive Measures}

Table 3 presents descriptive statistics for each scale, setting out the scale means and standard deviations, the number of items in each scale, the scale alphas, and the range of scores. It can be seen from Table 3 that reliability for all scales was satisfactory. Table 3 also presents descriptive statistics for single-item variables.

\section{Prejudice}

Before moving onto our specific aims, we briefly describe the wide range of views regarding Middle-Eastern Australians. Some were extremely negative; for example:

I feel that all the men that come from Afghanistan or Iraq should wear a yellow strip (sic) down their back for running away and leaving people from other countries to fight for them, as far as I am concerned they are cowards and should be treated as such. (Participant No. 149, 55-year-old male, qualitative responses to survey)

As has been found in other surveys measuring attitudes to Muslim Australians, the extremely prejudiced group was a minority (e.g., Griffiths \& Pedersen, 2009); however, given that prejudiced people are more likely to believe that their views are majority views (Pedersen, Griffiths, \& Watt, 2008) and thus be more vocal (Miller, 1993), their views are influential. Aside from the hurt these attitudes can inflict on Middle-Eastern Australians (HREOC, 2004), critique and characterisations such as those above can influence community attitudes in a negative, prejudiced, direction. Prejudiced attitudes such as these are likely to be difficult to shift, and are often based on negative emotion, not facts (Pedersen \& Fozdar, 2010). Yet this type of view was in the minority. Offsetting this was an example from the other end of the prejudice continuum:

I have spent time working with Middle Eastern refugees. They were honourable and good people. I have also had a lot of contact and lived in Kuwait for one month. Those people were very good to me and I was taken into their family. We are all citizens of this earth and the sooner we stop promoting fear of our neighbours the better it will be for us all. (Participant No. 135, a 62-year-old female, qualitative responses to survey)

\section{The Perception of Whether Middle-Eastern Australians Face Discrimination}

Regarding the Self-Discrimination Scale, just over half the participants (59\%), reported they were not discriminated against. As to those who reported that they were discriminated against, the categories in order of prevalence were gender $(15 \%)$, age $(11 \%)$, ethnicity $(10 \%)$, religion $(2 \%)$, 'other' $(2 \%)$ and sexuality $(1 \%)$. Scores on the SelfDiscrimination Scale were below the midpoint (between never and hardly ever); however, scores were higher on the Middle Eastern Discrimination Scale (around sometimes). As a whole, participants scored significantly higher on the Discrimination against Middle-Eastern Australians compared with the Self-Discrimination Scale, $t(74)=-12.6$, $p<.001$. This relationship was not significantly affected by SES. This demonstrates a good deal of public acknowledgment that Middle-Eastern Australians endure a discriminatory burden in Australia.

Low SES participants were more likely to report experiencing discrimination than those in high SES suburbs, $F(2,67)=3.7, p=.029$. There were more Causasian/European people in the high and medium SES categories (95\% and 92\% respectively) than the low SES category $(67 \%)$. That low SES participants were more likely to report experiencing discrimination than high SES participants is not surprising. Certainly, low SES can contribute to the experience of discrimination such as getting a job, somewhere to live and community resources (Paradies et al., 2009). It is very likely that discrimination would be magnified by being poor; apart from anything else, less respect is generally given to those less well off, to blue-collar workers and to nonprofessionals (Young, 1990). Also, many low SES areas in Sydney and Perth are places of greater economic struggle and of recent immigrant settlement (Burnley, 2001).

For the participants who perceived that discrimination against Middle-Eastern Australians did exist, a thematic analysis was conducted (Braun \& Clarke, 2006). We used an exploratory inductive approach; that is, we did not hypothesise what we might find but followed the data (Glaser \& Strauss, 1980) and used a 'bottom-up' process (Braun \& Clarke, 2006, p. 83). The thematic analysis was conducted by a paid research assistant who was unaware of the aims of the paper. Five major themes emerged and are described in order of prevalence. We note that some themes overlap; they are not mutually exclusive. Following the method adopted by Pedersen and Fozdar (2010), each theme was examined separately.

Theme 1: Values. Twenty-nine per cent of participants noted that there was a perception in the Australian community of a conflict between 'Middle Eastern culture' and 'core Australian values' and/or the concern that MiddleEastern Australians would not integrate. As Participant 
No. 107, a 24-year-old female, stated: 'I think that MiddleEastern Australians face potential discrimination due to the fact they don't fit in, they try and live to their Middle Eastern ways in a Western country. This is Australia they should live and respect our country and a large majority don't!' [participant's emphasis]. While there is a dearth of research on values and prejudice against Middle-Eastern Australians specifically, our findings are consistent with previous research with other marginalised groups. More specifically, previous survey participants report that their attitudes are highly influenced by their values; this has been found with respect to Muslim and Indigenous Australians (Griffiths \& Pedersen, 2009), African immigrants (Khan \& Pedersen, 2010), and asylum seekers (Pedersen et al., 2008). Conformity to Australian values was particularly important in a study by Pedersen and Hartley (2012). In this study, participants were asked whether their views about Muslim Australians were affected by their values, and if they were, in what way. Of those participants who did see their values as being important, approximately one-third reported that conformity to Australian culture, as they saw it, was important.

Theme 2: Fear of Muslims/Islam. The second theme reported by $28 \%$ of participants was fear and/or discomfort of Muslims, and Islam more generally; as Participant No. 6, a 64-year-old female argued: 'Unfortunately recent events and terrorism have fed people's fears'. This is not surprising given some results from the Challenging Racism Project (2011). These authors used a Bogardus scale to test the degree of social distance that people felt towards a series of minority groups. At the national level, Muslims were the group about whom there was most discomfort. There are two problems with the linking of Middle-Eastern Australians with a fear of Muslims, which can be seen by the above quote. The first is that not all Muslim Australians come from a Middle Eastern background. Another is that even if we are talking about Middle Eastern Muslims, they are not a homogenous group in terms of religion (Haddad, 2003), any more than Christian people are (James, Griffiths, \& Pedersen, 2011).

Theme 3: Terrorism. Nineteen per cent of participants reported that people make a connection between Australians of Middle Eastern descent and terrorism. As Participant No. 134, a 47-year-old female, put it: 'I think it would occur because people tend to associate Middle Eastern people with terrorism and fanaticism, rather than trying to understand what makes them function within their society, plus people always love reading and watching negative things, rather than positive, it's human nature!' This emphasis on stereotypes of violence and terrorism supports previous research. For example, in one Australian study, people who were more prejudiced against Muslim Australians also showed a higher fear of terrorism (Griffiths \& Pedersen, 2009).

Theme 4: Negative media portrayals. Fourteen per cent of participants reported negative media portrayals of Mid- dle Eastern people as possible sources for discrimination; for example, Participant No. 8 (a 64-year-old male) pointed to how 'Mass media appeals to and plays upon basic propensities for prejudice and simplistic thinking. A range of studies have pointed to the biased media reporting on Arab/Muslim issues in Australia (Dunn, Klocker, \& Salabay, 2007; Yasmeen, 2008) seen by some as stronger against Middle Easterners than other socially marginalised groups (Tehranian, 2007).

Theme 5: Fear of difference. A theme espoused by $11 \%$ of participants was a fear of difference. As Participant No. 17, a 47-year-old female, put it: 'Because people like and trust people who are similar to them and vice versa'. This comment echoes the arguments of numerous longstanding theories on intergroup relations and ethnocentrism. Indeed the observation would be recognisable as an important phenomenon to be explained in work dating back at least as far as that of Sumner (1906) and spanning approaches as diverse as those of Allport (1954), Tajfel and Turner (1979) and Turner, Hogg, Oakes, Reicher, \& Wetherell (1987).

In short, the distribution of the themes is not surprising. The most prevalent theme was people's values, and this supports past research that participants overwhelmingly based their attitudes on perceived values; these could relate to prejudiced or non-prejudiced views. Most relevantly, the attitudes and values across the five themes often referred to Muslim Australians. As noted elsewhere (Fozdar, Wilding, \& Hawkins, 2009) Muslim and Middle Eastern are often used interchangeably.

\section{Gendered Prejudice}

Regarding prejudice against Middle-Eastern females, mean scores were 'slightly favourable'; conversely, with respect to Middle-Eastern males, mean scores were 'slightly unfavourable'. Participants were significantly more negative about Middle-Eastern males $(M=53.5)$ than MiddleEastern females, $M=38.8, t(174)=9.4, p<.001$. This supports previous research into prejudice against Muslim Australians (Pedersen \& Hartley, 2012) and the results of Study 1 here. That this gender differentiation may be due to the conflation of Middle Eastern with Islam has been discussed above. As Aly (2007) notes, the media plays upon the concept of the oppressive Muslim man and the oppressed Muslim woman. For example, one of our participants noted: 'Most [Middle-Eastern Australians] are Muslim and it's a religion which represses women' (Participant No. 153, a 51-year-old female). This uneven stereotyping of Muslims across gender provides a sense of why there might be varied attitudes towards Middle-Eastern males and females, and why attitudes would be more negative towards Middle-Eastern males than females.

\section{General Discussion}

Tehranian (2007, p. 47) has argued that in the span of a generation, Middle Easterners have become the 
quintessential "other" in American society'. Similar sentiments have been found in the Australian setting (e.g., Sumner, 1906). 'Moral panics' about Middle-Eastern Australians are often supported by government statements (Poynting, 2006) and in media representations (Foster, Cook, Barter-Godfrey, \& Furneaux, 2011). As noted over 50 years ago, to reduce prejudice one must have the support of institutional authorities (Allport, 1954). Unfortunately, political action to assuage the prejudice faced by Middle-Eastern Australians has been overshadowed by the political deployment and cultivation of such prejudice. Researchers have demonstrated the political misuse and abuse of such attitudinal prejudice for electoral benefit (Dunn et al., 2007; Lygo, 2004; Pedersen, Watt, \& Hansen, 2006; Marr \& Wilkinson, 2003).

Findings from Study 2 indicate that highly prejudiced Australians were in the minority. However, even those relatively small numbers can have a powerful effect on both the targets of such prejudice and society as a whole. At the same time, there is a broad level of acknowledgment that Middle-Eastern Australians endure an elevated burden of discrimination, which is a strong basis from which to leverage public support for anti-prejudice initiatives.

Attitudes towards minority groups are important insofar as they affect community relations. As noted, negative attitudes can inappropriately influence hiring decisions and social interactions, thus underpinning discrimination and exclusion (e.g., Booth et al., 2009). Results from Study 1 indicated that relatively few Middle-Eastern Australians faced frequent discrimination. However, across all spheres of life, Middle Eastern participants experienced higher levels of discrimination than other Australians. This confirms similar assertions reported in government and NGO inquiries (HREOC, 2004; IWWCV; 2008) as well as in victim surveys and reports (Dreher, 2005; Poynting et al., 2004). Middle-Eastern Australians, in company with a handful of other communities, shoulder a higher burden of prejudice and discrimination.

Gender differences in the experience of discrimination were apparent, with Middle-Eastern males reporting higher rates of discriminatory encounters with police, and through prejudicial statements of disrespect, distrust and name calling. The links between prejudicial attitudes and discriminatory acts is well deserving of further research. However, the varied ways in which those links are refracted through gender are especially deserving of further attention.

While context was not our focus in the present article, an interesting avenue for future research involves these contextual findings. It would be useful to investigate particular locations with different demographics in an attempt to fine-tune any anti-prejudice intervention (cf. Forrest \& Dunn, 2007).

Our final and more positive comment is that while there is too much stated negative feeling towards MiddleEastern Australians, the rates of exposure to frequent discrimination by Middle-Eastern Australians is low (even though it is higher than for most Australians). This suggests that most ill-feeling does not necessarily convert into discriminatory acts. Further understanding the factors that can curtail and disrupt the links between prejudice and discrimination is as important as ever, and there may be important gender dynamics to these disruptions.

\section{Acknowledgments}

We thank Karin Maeder-Han for her help with the quantitative data with Study 1 and Lisa Hartley for her help with the qualitative data in Study 2. We also thank Phillip Hendry, Dasha Lvov, Leonie Patrice, Tamika Reid, Merinda Simpson, Caitlin Sullivan, and Neill Wilson for collecting and inputting the data for Study 2.

\section{Endnote}

1 We have made a comparison between 'Middle-Eastern Australians' and 'other Australians' in both Study 1 and Study 2. The Challenging Racism data show, however, that other marginalised groups such as Indigenous Australians and Asian Australians are also the target of discrimination (see Dunn, Forrest, Burnley \& McDonald, 2004) as are Indian and Sri Lankan people in Australia (Dunn, Gandhi, Pelleri, \& Maeder-Han, 2011). However, because the focus of our two-study paper is on attitudes towards Middle-Eastern Australians, we do not take this further.

\section{References}

Allport, G.W. (1954). The nature of prejudice. Cambridge, MA: Addison-Wesley.

Aly, A. (2007). Australian Muslim response to the discourse of terrorism in the Australian popular media. Journal of Social Issues, 42, 27-40.

Ata, A, Bastian, B., \& Lusher, D. (2009). Intergroup contact in context: The mediating role of social norms and group-based perceptions on the contact-prejudice. The International Journal of InterculturalRelations, 33, 498-506.

Australian Bureau of Statistics (ABS). (2010). Country of birth (region) by age by sex (Cat. No. 2068.0 - 2006 Census Tables). Retrieved from http://www.censusdata.abs.gov.au

Barlow, F.K., Louis, W., \& Hewstone, M. (2009). Rejected! Cognitions of rejection and intergroup anxiety as mediators of the impact of cross-group friendships on prejudice. British Journal of Social Psychology, 48, 389-405.

Booth, A., Leigh, A., \& Varganova, E. (2009). Does racial and ethnic discrimination vary across minority groups? Evidence from a field experiment. Canberra, Australia: Mimeo, Australian National University.

Bouma, G., Cahill, D., Dellal, H., \& Zwartz, A. (2011). Freedom of religion and belief in 21st century Australia. Canberra, Australia: The Australian Human Rights Commission.

Braun, V., \& Clarke, V. (2006). Using thematic analysis in Psychology. Qualitative Research in Psychology, 3, 77-101.

Burnley, I.H. (2001). The impact of immigration on Australia: A demographic approach. Melbourne, Australia: Oxford University Press. 
Challenging Racism Project. (2011). Challenging racism - findings, challenging racism: The Anti-Racism Research Project. Retrieved from http://www.uws.edu.au/social_sciences/ soss/research/challenging_racism/findings_by_region

Colic-Peisker, V. (2009). Visibility, settlement success and life satisfaction in three refugee communities in Australia. Ethnicities, 9, 175-199.

Deen, H. (1995). Caravanserai: Journey among Australian Muslims. Sydney, Australia: Allen \& Unwin.

Department of Immigration and Citizenship (DIAC). (2011). Settlement Reporting Facility. Retrieved from http://www.immi.gov.au/living-in-australia/deliveringassistance/settlement-reporting-facility/produce-report. htm.

Dreher, T. (2005). Targeted: Experiences of racism in NSW after September 11, 2001. Sydney, Australia: University of Technology Sydney Press.

Dunn, K.M. (2009). Performing Australian nationalisms at Cronulla. In G. Noble (Ed.), Lines in the sand: The Cronulla riots, multiculturalism and national belonging (pp. 76-94). Sydney, Australia: Institute of Criminology Press.

Dunn, K.M., Handhi, V., Burnley, I.H., \& Forrest, J. (2003). Racism in Australia: cultural imperialism, disempowerment and violence. In Gao J., Letterman R. \& Logie J. (Eds.), Windows on a Changing World - Proceedings of the 22nd New Zealand Geographical Society Conference (pp. 175-179). Palmerston North, New Zealand: New Zealand Geographical Society.

Dunn, K.M., Klocker, N., \& Salabay, T. (2007). Contemporary racism and Islamaphobia in Australia: Racialising religion, Ethnicities, 7, 564-589.

Dunn, K.M., Forrest, J., Burnley, I., \& McDonald, A. (2004). Constructing racism in Australia. Australian Journal of Social Issues, 39, 409-430.

Dunn, K.M., Gandhi, V., Pelleri, D., \& Maeder-Han, K. (2011). Racism in the tertiary education sector: A case of Indian student attacks in Australia. Geography Bulletin, 43, 7-16.

Forrest, J., \& Dunn, K.M. (2007). Constructing racism in Sydney, Australia's largest ethni-city. Urban Studies, 44, 699-721.

Foster, N., Cook, I., Barter-Godfrey, S., \& Furneaux, S. (2011). Fractured multiculturalism: Conflicting representations of Arab and Muslim Australians in Australian print media. Media, Culture \& Society, 33, 619-629.

Fozdar, F., Wilding, R., \& Hawkins, M. (2009). Anti-racism. In F. Fozdar, R. Wilding \& M. Hawkins (Eds.), Race and ethnic relations (pp. 256-285). Melbourne, Australia: Oxford University Press.

Glaser, B., \& Strauss, A. (1980). The discovery of grounded theory: Strategies for qualitative research (11th ed.). New York: Aldine Transaction.

Griffiths, B., \& Pedersen, A. (2009). Prejudice and the function of attitudes relating to Muslim Australians and Indigenous Australians. Australian Journal of Psychology, 61, 228-238.

Haddad, S. (2003). Islam and attitudes toward U.S. policy in the Middle East: Evidence from survey research in Lebanon. Studies in Conflict and Terrorism, 26, 135-154.
Haslam, N., \& Pedersen, A. (2007). Attitudes towards asylum seekers: The psychology of prejudice and exclusion. In D. Lusher \& N. Haslam (Eds.), Yearning to breathe free:Seeking asylum in Australia (pp. 208-218). Sydney, Australia: Federation Press.

Human Rights and Equal Opportunity Commission (HREOC). (2004). Ismac Listen: National consultations on eliminating prejudice against Arab and Muslim Australians. Sydney, Australia: Author.

Islamic Council of New South Wales (ICNSW). (2004). Challenges for Australian Muslims: Discrimination, anti-terrorism, and the media. Sydney, Australia: Islamic Council of New South Wales.

Islamic Women's Welfare Council of Victoria (IWWCV). (2008). Race, faith and gender: Converging Discriminations against Muslim women in Victoria: The ongoing impact of September 11, 2001. Melbourne, Australia: Author.

James, W., Griffiths, B., \& Pedersen, A. (2011). Religious beliefs and prejudice against Australian Muslims and gays \& lesbians. International Journal for the Psychology of Religion, 21, 212-227.

Khan, S., \& Pedersen, A. (2010). Black African immigrants to Australia: Prejudice and the function of attitudes. Journal of Pacific Rim Psychology, 4, 116-129.

Klocker, N. (2004). Community antagonism towards asylum seekers in Port Augusta, South Australia. Australian Geographical Studies, 42, 1-17.

Lygo, I. (2004). News overboard: The tabloid media, race politics and Islam. Sydney, Australia: Southerly Change Media.

Marr, D., \& Wilkinson, M. (2003). Dark victory. Sydney, Australia: Allen \&Unwin.

Miller, C.T. (1993). Majority and minority perceptions of consensus and recommendations for resolving conflicts about land use reform. Personality \& Social Psychology Bulletin, 19, 389-398.

Paradies, Y., Chandrakumar, L., Klocker, N., Frere, M., Webster, K., Burrell, M., \& McLean, G. (2009). Building on our strengths: A framework to address race-based discrimination and support diversity in Victoria. Melbourne, Australia: Victorian Health Promotion Foundation:

Pedersen, A., \& Fozdar, F. (2010). Refugee without refuge: Wasim, Phillip Adams, and a nation divided. Journal of Pacific Rim Psychology, 4, 7-18.

Pedersen, A., Griffiths, B., \& Watt, S. (2008). Attitudes toward outgroups and the perception of consensus: All feet do not wear one shoe. Journal of Community and Applied Social Psychology, 18, 543-557.

Pedersen, A., \& Hartley, L.K. (2012). Prejudice against Muslim Australians: The role of values, gender and consensus. Journal of Community and Applied Social Psychology, 22, 239255.

Pedersen, A., Watt, S., \& Hansen, S. (2006). The role of false beliefs in the community's and the federal government's attitudes toward Australian asylum seekers. Australian Journal of Social Issues, 41(1), 105-124. 
Poynting, S. (2006). What caused the Cronulla riot? Race and Class, 48, 85-91.

Poynting, S., Noble, G., \& Ang, L. (2004). The experience and reporting by Arab and Muslim Australians of discrimination, abuse and violence since 11 September 2001. Retrieved from http://www.humanrights.gov.au/racial_discrimination/isma/ research/index.html

Poynting, S., Noble, G., \& Tabar, P. (1999). Intersections of masculinity and ethnicity: A study of male Lebanese immigrant youth in western Sydney. Race Ethnicity and Education, 2, 59-78.

Runions, K., Priest, N., \& Dandy, J. (2011). Discrimination and psychological adjustment among Australian children from Middle-Eastern and Asian backgrounds. Australian Community Psychologist, 23, 23-33.

Salleh-Hoddin, A., \& Pedersen, A. (in press). Being Muslim in Australia: Experiences of discrimination and protective factors for integration. The Australian Community Psychologist.

Sumner, W.G. (1906). Folkways: A study of the sociological importance of usages, manners, customs, mores, and morals. Boston: Ginn \& Co.
Tajfel, H., \& Turner, J.C. (1979). An integrative theory of intergroup conflict. In W.G. Austin \& S. Worchel (Eds.), Social psychology of intergroup relations (pp. 33-48). Belmont, CA: Wadsworth.

Turner, J.C., Hogg, M.A., Oakes, P.J., Reicher, S.D., \& Wetherell, M. (1987). Rediscovering the social group: A self-categorization theory. Oxford: Blackwell.

Tehranian, J. (2007). Compulsory whiteness: Towards a Middle Eastern legal scholarship. Indianan Law Journal, 82(1), 1-47.

Tilbury, F., \& Colic-Peisker, V. (2006). Deflecting responsibility in employer talk about race discrimination, Discourse and Society, 17, 651-676.

Wolsko, C., Park, B., Judd, C.M., \& Bachelor, J. (2003). Intergroup contact: Effects on group evaluations and perceived variability. Processes \& Intergroup Relations, 6, 93-110.

Yasmeen, S. (2008). Understanding Muslim identities: From perceived relative exclusion to inclusion. Perth, Australia: University of Western Australia

Young, I.M. (1990). Justice and the politics of difference. Princeton, NJ: Princeton University Press. 